Acta Technologica Agriculturae 3

Nitra, Slovaca Universitas Agriculturae Nitriae, 2021, pp. 124-128

\title{
DEVELOPMENT AND RESEARCH OF NEW MEDIA JET AERATION SCHEME IN A LOOP BIOREACTOR PRODUCING MICROBIOLOGICAL PRODUCTS
}

\author{
Vladislav YAROSHEVSKY ${ }^{1}$, Valentyna KRUTYAKOVA', Volodymyr BELCHENKO', \\ Semjons IVANOVS ${ }^{2 *}$, Volodymyr BULGAKOV ${ }^{3}$ \\ 'Engineering and Technology Institute "Biotechnica", National Academy of Agrarian Sciences of Ukraine, Ukraine \\ ${ }^{2}$ Latvia University of Life Sciences and Technologies, Jelgava, Latvia \\ ${ }^{3}$ National University of Life and Environmental Sciences of Ukraine, Ukraine
}

\begin{abstract}
Jet aeration loop reactors are widely used in the chemical industry due to their high mixing intensity, possibility of significant saturation of medium with gases, and simplicity of scaling the processes when passing from laboratory equipment to industrial designs. However, to ensure the necessary amount of air in standard jet aeration schemes with ejectors, high pressure of the medium (up to 6 bars) is required in the reactor loop. This paper presents a newly developed scheme of jet aeration, based on mixing the pressure flows of medium and air supplied to the ejector by individual blowers. Experiment results of the new water aeration scheme showed that, for the formation of suspended matter in the ejector with an air content of 2-20 I per 1 I of water, a pressure of 0.3 bar in the reactor loop at an air pressure of 1 bar is sufficient. This allows usage of low-pressure pump and compressor, which form the basis for the energy consumption reduction and creates prerequisites for lowering the shear loads on a crop. The medium aeration rate during experiments was $0.220-0.266 \mathrm{vvm}$. It was found that, for each mode of joint operation of pump and compressor, it is possible to maintain a constant aeration rate, which is not significantly affected by the flowrate regulation of medium in loop.
\end{abstract}

Keywords: pressure; flow; saturation; mixing; bioreactor; ejector

One of the factors limiting the growth of microorganisms during fermentation is insufficient saturation of the fermentation medium with oxygen (Stanbury et al., 2016; Beker, 1978). In contrast to other types of reactors, this problem is probably solved in the most appropriate manner in the jet loop bioreactors. This is achieved by jet mixing of a fermentation medium with air. As a result, the liquid uniformity is violated - a suspension is formed, and its saturation degree with air is much higher (Kim et al., 2012; Van Dierendonck et al., 1998).

The most frequent jet mixing scheme (Fig. 1a) proposes a method by mixing the liquid and gaseous media in an ejector and feeding the finished mixture into a bioreactor (Ughetti et al., 2018; Moresi et al., 1983). In addition, the fermentation medium in loop is conveyed to the ejector nozzle, performing the function of a motive fluid, but the air is sucked in. The mixture, saturated with air, can be either sprayed onto the medium surface in reactor or supplied in doses (Warmeling et al., 2016; Meyer and Charles, 1982). The aeration rate in jet loop bioreactors may vary over a wide range from 0.25 ... to $2.0 \mathrm{vvm}$ (Ughetti et al., 2018; Weber et al., 2018a; Moresi et al., 1983). Furthermore, due to the mixing of media in ejector (and not in apparatus), a more uniform distribution of air in medium and its greater oxygen saturation are ensured (Weber et al., 2018b). The disadvantage of described scheme is the dependence of amount of sucked air on the fermentation medium pressure created by pump in bioreactor loop. Therefore, if it is necessary to increase the amount of intake air, it is necessary to increase the medium pressure as well, which is achieved by increasing the number of pump revolutions or by replacing it with a more powerful one.

This situation can be addressed by adapting a jet aeration scheme that would allow separate solution of the issues of medium circulation through a loop and aeration. For these purposes, a new jet aeration scheme was developed (Fig. 1b), which supplies air to the ejector nozzle while the fermentation medium is pumped to the secondary flow pipe. In such a manner, the air flow, pumped by the compressor, will be injected into the pressure stream of fermentation medium. This allows, on the one hand, performing aeration, which is independent on the ejection process (jet ejection). On the other hand, this scheme makes it possible to reduce the pressure created by the pump, and hence its power consumption. In literature, there is a scarcity of descriptions of the jet mixing scheme of pressure flows of liquid and gas in an ejector during the gas supply through the nozzle ( $\mathrm{Li}$ et al., 2020). Consequently, it is rather difficult to theoretically estimate the medium aeration rate in loop bioreactor, as well as the other process parameters. Therefore, the aim of

Contact address: Semjons Ivanovs, Latvia University of Life Sciences and Technologies, 2 Liela Street, LV-3001 Jelgava, Latvia, e-mail: semjons@apollo.Iv 


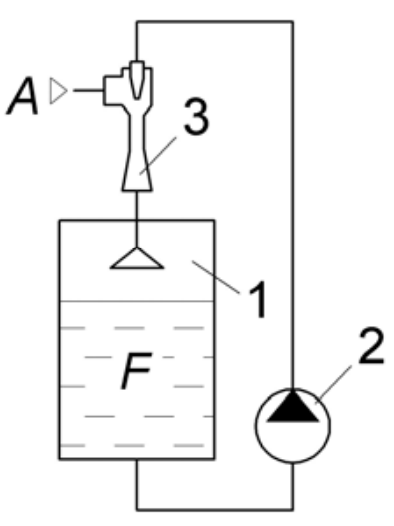

(A)

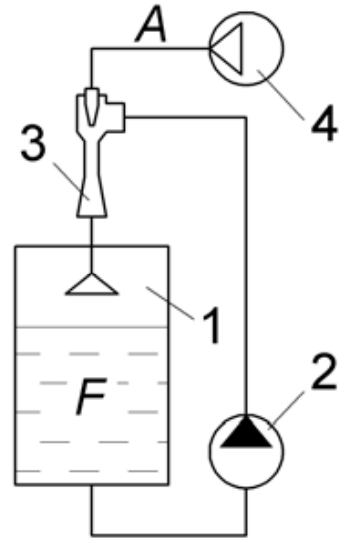

(B)
Fig. 1 Schemes of jet aeration in loop bioreactors: standard (a), new (b)

1 - bioreactor; 2 - pump; 3 - ejector; 4 - compressor, F fermentation medium; $\mathrm{A}$ - air

this work is to conduct an experimental study of the main characteristics of jet aeration, implemented according to the new scheme.

\section{Material and methods}

The operation parameters of new jet aeration scheme were determined using an experimental setup (of own design), the scheme of which is shown in Fig. 2 and based on a bioreactor (FTU-0.1, ETI "Biotechnica"). The bioreactor consists of a tank [1] with total volume of $100 \mathrm{I}$ and an external circulation line (loop) with pump (Wilo Star RS 15/5-3P) [2], which is designed for mixing the fermentation medium. The flow rate of medium in loop was regulated by throttling using a manual control valve [8]. Air for aeration was supplied by compressor (ABAC FC2/50 CM2) [3]. The airliquid mixture (obtained in ejector [4]) was sprayed onto the medium surface in tank [1] using sprayer [5]. The volumetric flow rates and the static flow pressures in front of ejector were determined using flow meters (Novator LK-15C) [6] (Arsenal G 2.5) [7], and pressure gauges (MTI from 0 to 0.6 bar) [9] and (MTI from -1 to + 3 bar) [10].

The design diagram of ejector [4], which was used in experimental setup (Fig. 2), is presented in Fig. 3. The ejector is a jet apparatus of a diffuser-free design consisting of housing [1] that was used as a standard three-way pipe (tee pipe) with a diameter of $15 \mathrm{~mm}$. On one side of the tee pipe [1], there is nozzle [2] with the diameter of $1.8 \mathrm{~mm}$, mounted inside the pipe passage $1 / 2^{\prime}-3 / 4^{\prime}[3]$ and sealed with the rubber insert [4]. The nozzle section (nozzle orifice) coincides with the axis of branch of tee pipe [1]. Air was supplied via a flexible hose to nozzle [2] and was sprayed into the fluid flow entering the branch of tee pipe [1]. Mixing of air and medium started in tee pipe [1] and continued in pipe [6] (with length of $100 \mathrm{~mm}$ and diameter of $15 \mathrm{~mm}$ ), supplying the mixture directly by the sprayer inside the bioreactor.

The fermentation medium in experiments was simulated using water that was preliminarily purified in a three-stage Ecosoft $10^{\prime}$ filter with polypropylene cartridges and micron

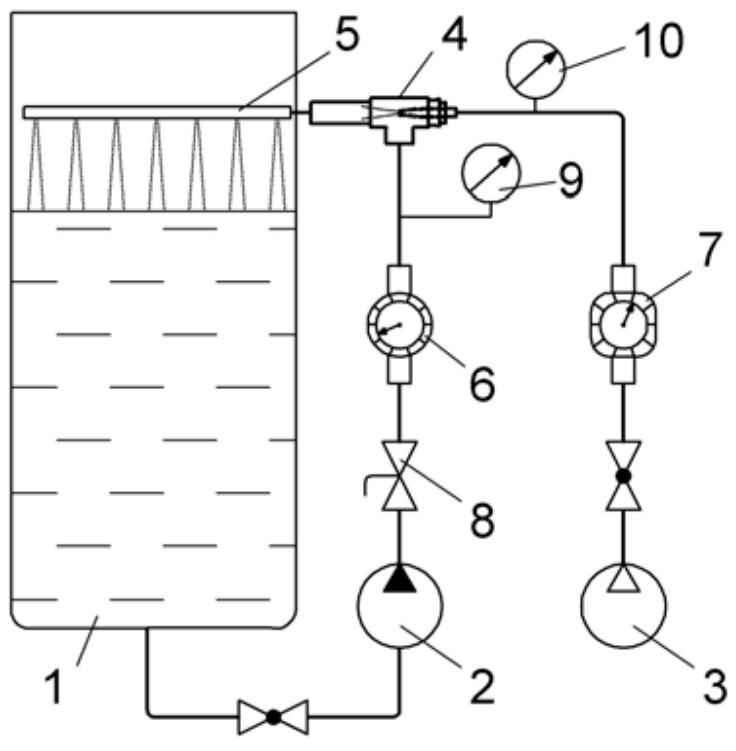

Fig. 2 Scheme of experimental setup based on a jet loop bioreactor (FTU-0.1, ETI "Biotechnica”)

1 - tank (100 I); 2 - pump (Wilo Star RS 15/5-3P); 3 - air compressor (ABAC FC2/50 CM2); 4 - ejector; 5 - sprayer; 6 - liquid flow meter (Novator LK-15C); 7 - air flow meter (Arsenal G 2.5); 8 - balancing valve; 9 - pressure gauge (MTI from 0 to 0.6 bar); 10 - pressure gauge (MTI from -1 to +3 bar)

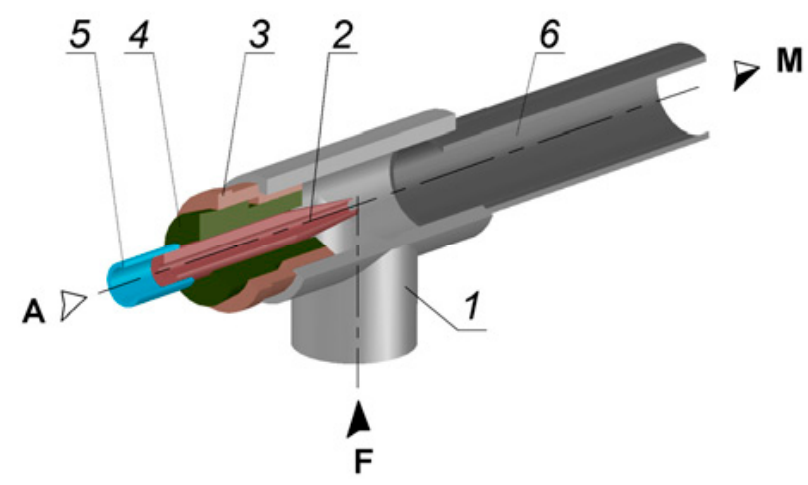

Fig. 3 Ejector design scheme

1 - housing (tee pipe); 2 - nozzle; 3 - adapter; 4 - sealer; 5 - flexible hose; 6 - pipe; A - air; F - fermentation medium; $\mathrm{M}$ - mixture

ratings of $10 \mu \mathrm{m}, 5 \mu \mathrm{m}$, and $1 \mu \mathrm{m}$. During the experiments, the bioreactor was filled with 50 I of water, which was then mixed for 20 minutes with air in selected mode. For the purposes of experiment, twelve modes of jet aeration were tested, depending on combination of the pump speed (2350 rpm, $2630 \mathrm{rpm}, 2720 \mathrm{rpm}$ ) and the air pressure at the compressor outlet (1.0 bar, 1.5 bar, 2.0 bar, 2.5 bar). The air and water temperatures in the experiments were $27^{\circ} \mathrm{C}$.

The flow rates of water and air were determined using flow meters [6], [7] (Fig. 2), and the static pressures were determined using pressure gauges [9], [10] (Fig. 2). Based on the values obtained according to the standard dependences (Bernoulli equation, continuity equation), the average cross-sectional flow velocities, the dynamic and total flow pressures before entering the ejector were calculated. 
The jet aeration modes were determined on the basis of dimensionless parameters as follows:

$$
\begin{gathered}
q=\frac{Q_{w}}{Q_{a}} \\
p=\frac{P_{a}^{t}}{P_{w}^{t}}
\end{gathered}
$$

where:

$q$ - relative flow rate; $p$ - relative pressure; $Q_{w^{\prime}} Q_{a}$ - volumetric flow rates of water and air flows $\left(1 \cdot \mathrm{min}^{-1}\right) ; P_{w^{\prime}}^{t} P_{a}^{t}-$ full pressures of water and air flows at the ejector entrance (bar)

Statistical processing of measurements was conducted using MS Excel (Divisi et al., 2017; Bulgakov et al., 2019) according to the standard method (Box et al., 2005; Zasadzień and Midor, 2018). During the data processing, the arithmetic mean values of measured values and standard deviation were determined; furthermore, the relative and absolute measurement errors were calculated for a confidence level of $95 \%$.

\section{Results and discussion}

In the course of experiments, various modes of jet aeration were studied (Fig. 4), which were based on different combinations of parameters of the flows of water and air, mixed in the ejector. Each curve in Fig. 4 was determined by a combination of parameters of the joint operation of compressor (pressure, bar) and pump (revolutions, rpm).

Analysis showed that the largest range of relative flow rates $q$ was achieved at a minimum air pressure (1 bar). This trend continued for all pump operating modes. The increase in the air pressure - indicated by the increase in relative pressure $p$ - led to a decrease in the range $q$. Since the relative flow rate shows the amount of water per unit of

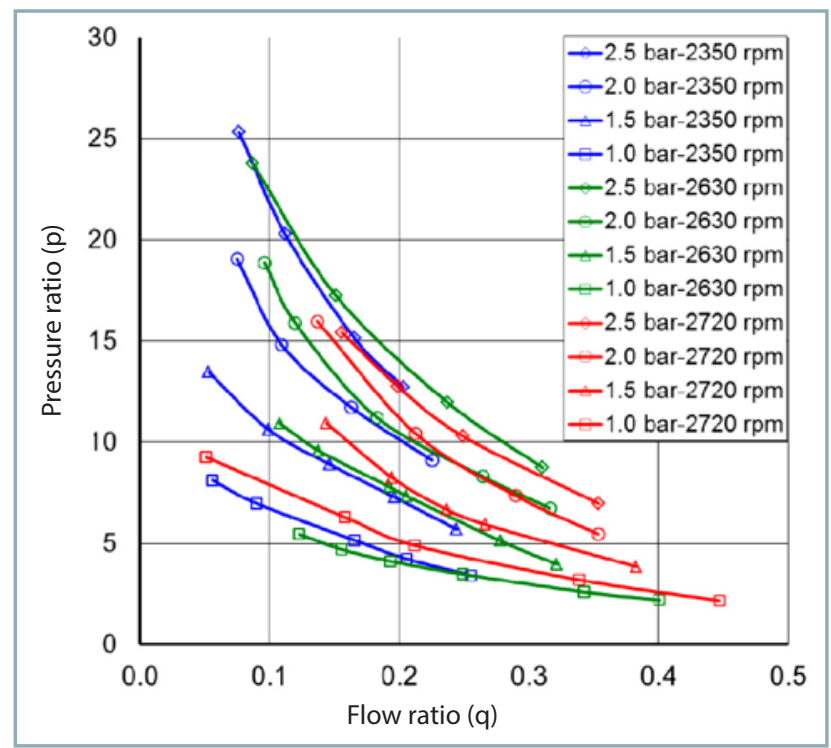

Fig. 4 Modes of jet aeration at different pump speeds (2350 rpm; 2630 rpm; 2720 rpm) and compressor air pressure (1 bar; 1.5 bar; 2 bar; 2.5 bar) volume of sprayed air at each time point (1), the minimum $q$ values correspond to the maximum amount of air supplied to the ejector. Subsequently, at the minimum value $q=0.05$ (curve $1 \mathrm{bar}-2720 \mathrm{rpm}$ ), $1 \mathrm{l} / \mathrm{q}=20 \mathrm{I}$ of air was sprayed to 1 litre of water at a time.

As it is known, the solubility of air in water is characterized by a very small value: 0.02 litres of air per 1 litre of water. Therefore, it is obvious that, when the amount of air exceeds the solubility by 3 orders of magnitude, the continuity of liquid will be violated, i.e. a suspension will form (Kim et al., 2012; Van Dierendonck et al., 1998). The fact of a suspension formation, confirmed by the results of our previous studies (Yaroshevsky et al., 2020), indicates a significant degree of liquid saturation with atmospheric oxygen. In this regard, spraying through the nozzle with a small diameter $(1.8 \mathrm{~mm})$ can contribute to a more uniform mixing of media without the formation of large air voids in the flow.

It should be noted that the value $q$ characterises aeration of only that part of the medium that is currently in the ejector. In order to characterise the aeration of entire medium volume in bioreactor, another parameter was used - the aeration rate. In general, the aeration rate is defined as the ratio of air volume to medium volume per minute (Soderberg, 2014):

$$
A=\frac{V_{a}}{V_{f}} \frac{1}{\tau}
$$

where:

$A$ - aeration rate (vvm); $V_{a}, V_{f}$ - air volumes sprayed into the fermentation medium volume (I), during time $\tau$ (min)

In the jet loop bioreactor, the air flow is mixed with medium flow in the ejector. Therefore, it is convenient to consider the volumetric flows $Q_{a}$ and $Q_{f}$ of the media mixed in ejector as the characteristics of these flows, and not the volumes:

$$
A=\frac{Q_{a}}{Q_{f}} \frac{1}{\tau}
$$

In this case, $\tau$ showed the transit time of entire medium volume contained in bioreactor through the ejector, i.e. $\tau$ is the time necessary for complete single circulation of medium through the reactor loop. Taking into account Eq. 1, as applied to the experiment conditions, the ratio of volumetric rates can be rewritten as follows:

$$
\frac{Q_{a}}{Q_{f}}=\frac{1}{q}
$$

Concurrently, Eq. 4 for determination of the aeration rate in jet loop reactor will assume the form:

$$
A=(q \cdot \tau)
$$

In the experiments, $\tau$ was determined through the ratio of total volume of water in reactor $(50 \mathrm{l})$ to the pump flow rate. The calculations, performed according to Eq. 6 for the entire array of experimental data, showed that an increase 
Table 1 Average values of the aeration rate for different modes

\begin{tabular}{|l||c|c|c|}
\hline \multicolumn{1}{|l||}{$\begin{array}{l}\text { Air compressor } \\
\text { outlet pressure (bar) }\end{array}$} & \multicolumn{3}{|c|}{ Values of the aeration rate with deviations, } \\
$\boldsymbol{A}_{\boldsymbol{m}} \pm \delta$ (v) (vv) \\
\hline $\mathbf{2 . 5}$ & $0.263 \pm 0.003$ & $0.263 \pm 0.002$ & $0.266 \pm 0.001$ \\
\hline $\mathbf{2 . 0}$ & $0.260 \pm 0.002$ & $0.262 \pm 0.002$ & $0.263 \pm 0.001$ \\
\hline $\mathbf{1 . 5}$ & $0.253 \pm 0.006$ & $0.256 \pm 0.005$ & $0.256 \pm 0.005$ \\
\hline $\mathbf{1 . 0}$ & $0.220 \pm 0.004$ & $0.223 \pm 0.006$ & $0.234 \pm 0.007$ \\
\hline \multicolumn{3}{|c|}{ Pump impeller speed (rpm) } \\
\hline & 2350 & 2630 & 2720 \\
\hline
\end{tabular}

in the relative flow rate $q$ within the framework of a single aeration mode leads to insignificant changes in the aeration rate $A$. For each $p$ - $q$ curve (Fig. 4) for each aeration mode, insignificant fluctuations of $A$ were observed relative to a certain average value of $A_{\text {mid }}$ (Table 1). The deviation value $\delta$ of current aeration value rate $A$ from the average $A_{\text {mid }}$ did not exceed $\delta=$ $\pm 3 \%$, allowing to consider the aeration rate a constant value for each mode of aeration. In this case, the aeration rate is determined by the combination of parameters of joint operation of pump and compressor, and it does not depend on the regulation of water flow by throttling, which leads to a change in q within the framework of the mode.

Considering the Table 1 , it is evident that the range of values for aeration rate of tested modes was small: $A=0.220$ $0.266 \mathrm{vvm}$. Therefore, an increase in the air pressure from 1 bar to 2.5 bars leads to quite an insignificant increase in the aeration rate (up to $0.042 \mathrm{vvm}$ ). An even smaller increase in $A$ can be achieved by increasing the impeller speed at a constant air pressure. In such a manner, the regulation of flow parameters does not lead to a significant change in the aeration degree. In our opinion, this is due to the ejector geometry invariability.

As it is known, the mixing parameters of flows in ejectors and jet pumps (primarily q) are determined

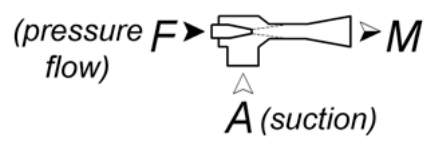

(a)

Fig. 5 Modes of operation of the ejector with standard (a) and new (b) scheme of jet aeration

$F$ - fermentation medium; $A$ - air by the ratio of diameters of both the nozzle and neck to a large extent (Cunningham, 2001; Sokolov and Zinger, 1989). At a constant ratio of these diameters, the regulation range of ejector relative flow rate is extremely small. Due to this property, devices of this type are often used as dispensers. Consequently, a significant change in the relative flow rate, and hence the aeration rate, can only be achieved by changing the ejector geometry. The simplest way to achieve thus is to increase the nozzle diameter.

The standard scheme of jet aeration in a loop reactor, as mentioned above, relies on the air suction of by fermentation medium flow, supplied to the ejector nozzle (Fig. 5a). However, application of this scheme for industrial bioproduction faces a number of difficulties. To ensure the required aeration rate, a large pressure of liquid is required (up to 6 bars) in before the nozzle. The development of such pressure by pump is associated with a high rotation speed of impeller. This, in its turn, leads to a significant increase in slice loads on cells, leading to inhibition of the biomass growth (Ughetti et al., 2018; Weber et al., 2018a; Moresi et al., 1983). The situation is complicated by a need to ensure aseptic conditions: before entering the ejector, air must be cleaned from mechanical impurities and disinfected (Stanbury et al., 2016; Soderberg, 2014;

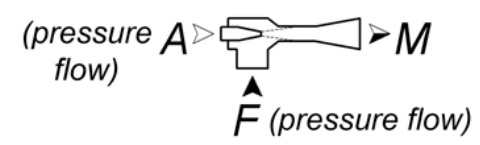

(b)
Beker, 1978). Accordingly, the air supply line often has a high aerodynamic resistance, and it is necessary to create a significant vacuum in the ejector in order to overcome it. On one hand, it is necessary to ensure a high pressure on the ejector nozzle for the purposes of air suction. On the other hand, an increase in pressure leads to the cell death in the pump impeller. The complexity of combining these two opposite requirements in one device has apparently led only to an insignificant distribution of the jet loop reactors in biotechnology.

Proposed approach for solving this issue is based on changing the ejector operating mode from air suction by medium flow (Fig. 5a) to mixing both pressure flows (Fig. 5b). Such a scheme allows adjusting the flow parameters of fermentation medium and air into the ejector independently of each other. Experimental studies using an ejector of the simplest design revealed certain technical advantages of this scheme.

Firstly, the amount of air mixed to medium in the ejector is regulated over a wide range (from 2 to 20 litres of air per 1 litre of medium). To ensure this range, a compressor pressure of 1 bar is quite sufficient, which allows the use of low-pressure compressors with a rated power of less than 100 watts, which is 8 times less than the compressor power used in experiments. It should be emphasized that these large energy expenditures for the compressor operation were one of the reasons for the development of loop reactors with jet aeration, as an alternative to the bubble columns and apparatus with a stirrer (certain tank bioreactors) (Ughetti et al., 2018; Weber et al., 2018b; Meyer and Charles, 1982)

Secondly, the new jet aeration scheme can significantly reduce the pump pressure moving the fermentation medium through reactor loop. In standard scheme, the pump pressure has to be at least 3 bars in order to ensure air intake (Weber et al., 2018a; Moresi et al., 1983); for the jet aeration based on new scheme, the sufficient pump pressure is 0.3 bar. Such decrease in pressure not only leads to a decrease in the pump electric power but also helps to reduce shear loads on the impeller cells. 
The aeration rate values (up to $0.26 \mathrm{vvm}$ ) obtained in experiments are sufficient for the cultivation of a number of biopesticides based on the bacteria Bacillus thuringiensis (Rahbani et al., 2015; Silva et al., 2011). However, production of biopesticides based on other cultures of microorganisms requires large degrees of aeration (Lacey, 2016). This investigation showed that increasing the aeration rate can be achieved by increasing the diameter of ejector nozzle, i.e. without increasing the size of pump or compressor.

\section{Conclusion}

1. Functional tests of proposed aeration scheme showed that, when air is sprayed into the fluid stream through a nozzle with small diameter $(1.8 \mathrm{~mm})$, a suspension is formed with an air content of 2 I to 20 I per 1 I of water. This range of flow ratios can be achieved at a medium pressure in the loop of less than 0.3 bar and an air pressure in front of the ejector nozzle of 1 bar. Consequently, for the jet aeration of medium, it is possible to use a lowpressure pump and compressor, which are the main factors in reducing power consumption for mixing and aeration. Reducing the pump pressure from 3 bars to 0.3 bar is a prerequisite for reducing the shear stresses on culture, and hence reducing the biomass growth inhibition, which is characteristic for the loop bioreactors.

2. Developed scheme allows achieving of a small aeration rate of medium at $(0.22-0.27 \mathrm{vvm})$ using a simple ejector with small nozzle diameter $(1.8 \mathrm{~mm})$, and it is sufficient to produce a number of biopesticides. This scheme is characteristic by maintaining a practically constant value of the aeration rate for each mode of aeration, which is determined by a combination of parameters of compressor and pump working together; the aeration rate is not essential for regulation of the medium flow rate in loop.

3. Proposed jet aeration scheme allows separate solution of the issues with aeration and mixing of fermentation medium by circulation, helping to reduce the energy consumption and has a beneficial effect on the reactor operation in its entirety.

\section{References}

BEKER, M. 1978. Introduction to Biotechnology. Riga : Pischevaya promyshlennost, 231 pp. (In Russian: Vvedenie v biotehnologiju)

BOX, G. E. P. - HUNTER, J. S. - HUNTER, W. G. 2005. Statistics for Experimenters Design, Innovation, and Discovery. $2^{\text {nd }}$ ed. New Jersey : John Wiley \& Sons, Inc., 633 pp. ISBN 9780471718130.

BULGAKOV, V. - IVANOVS, S. - ADAMCHUK, V. - ANTOSHCHENKOV, R. 2019. Investigations of the dynamics of a four-element machineand-tractor aggregate. In Acta Technologica Agriculturae, vol. 22, no. 4, pp. 146-151.

CUNNINGHAM, R. G. 2001. Jet pump theory. In KARASSIK, I. J. - MESSINA, J. P. - COOPER, P. - HEALD, C. C. Pump Handbook. $3^{\text {rd }}$ ed. The McGraw-Hill Companies, Inc. : New York, 1765 pp. ISBN 0070340323.

DIVISI, D. - DI LEONARDO, G. - ZACCAGNA, G. - CRISCI, R. 2017. Basic statistics with Microsoft Excel: a review. In Journal of Thoracic Disease, vol. 9, no. 6, pp. 1734-1740.

KIM, Y. K. - LEE, D. Y. - KIM, H. D. - AHN, J. H. - KIM, K. C. 2012. An experimental and numerical study on hydrodynamic characteristics of horizontal annular type water-air ejector. In Journal of Mechanical Science and Technology, vol. 26, no. 9, pp. 2773-2781.

LACEY, L. 2016. Microbial Control of Insect and Mite Pests: From Theory to Practice. Academic Press : Amsterdam, 482 pp. ISBN 9780128035276.

LI, S. - LI, W. - LIU, Y. - JI, C. - ZHANG, J. 2020. Experimental investigation of the performance and spray characteristics of a supersonic two-phase flow ejector with different structures. In Energies, vol. 13, no. 5, article no. 1166.

MEYER, H. P. - CHARLES, M. 1982. Cultivation of a filamentous bacterium in a deep jet fermentor. In Biotechnology \& Bioengineering, vol. 24, no. 8. pp. 1905-1909.

MORESI, M. - BARTOLO GIANTURCO, G. - SEBASTIANI, E. 1983. The ejector-loop fermenter: description and performance of the apparatus. In Biotechnology \& Bioengineering, vol. 25, no. 12, pp. 2889-2904.

MOUNSEF, J. R. - SALAMEH, D. - LOUKA, N. - BRANDAM, C. - LTEIF R. 2015. The effect of aeration conditions, characterized by the volumetric mass transfer coefficient $\mathrm{KLa}$, on the fermentation kinetics of Bacillus thuringiensis kurstaki. In Journal of Biotechnology, vol. 210, pp.100-106.

DA SILVA, M. - FURIGO, A. - FURLAN, S. A. - SOUZA, O. 2011. Production of bio-inseticide Bacillus thuringiensis var. israelensis in semicontinuous processes combined with batch processes for sporulation. In Brazilian Archives of Biology and technology, vol. 54, no. 1, pp. 45-52.

SODERBERG, A. 2014. Fermentation design. In TODARO, C. C. - VOGEL, H. C. Fermentation and Biochemical Engineering Handbook. $3^{\text {nd }}$ ed. Amsterdam : William Andrew, pp. 85-108. ISBN 9781455725533.

SOKOLOV, E. - ZINGER, N. 1989. Jet Devices. Energia : Moscow, 352 pp. (In Russian: Vpryskivajushchie ustroistva)

STANBURY, P. - WHITAKER, A. - HALL, S. J. 2016. Principles of Fermentation Technology. $3^{\text {rd }}$ ed. Butterworth-Heinemann Ltd : Oxford, 824 pp. ISBN 9780080999531.

UGHETTI, M. - JUSSEN, D. - RIEDLBERGER, P. 2018. The ejector loop reactor: Application for microbial fermentation and comparison with a stirred-tank bioreactor. In Engineering in Life Sciences, vol. 18, no. 5, pp. 281-286.

VAN DIERENDONCK, L. L. - ZAHRADNÍK, J. - LINEK, V. 1998. Loop Venturi reactor a feasible alternative to stirred tank reactors? In Industrial \& Engineering Chemistry, vol. 37, no. 3, pp. 734-738.

WARMELING, H. - BEHR, A. - VORHOLT, A. J. 2016. Jet loop reactors as a versatile reactor set up - Intensifying catalytic reactions: A review. In Chemical Engineering Science, vol. 149, pp. 229-248.

WEBER, S. - SCHAEPE, S. - FREYER, S. - KOPF, M.-H. - DIETZSCH, C. 2018a. Jet aeration as alternative to overcome mass transfer limitation of stirred bioreactors. In Engineering in Life Sciences, vol. 18, no. 4, pp. 244-253.

WEBER, S. - SCHAEPE, S. - FREYER, S. - KOPF, M.-H. - DIETZSCH, C. 2018b. Effect of ejector operation on the oxygen transfer in a pilot jet loop reactor. In Chemical Engineering and Processing, vol. 131, pp. 45-50.

YAROSHEVSKY, V. - BULGAKOV, V. - IVANOVS, S. - KRUTYAKOVA, V. - BELCHENKO, V. - OLT, J. 2020. Research on the impact of the air-liquid jet mixer upon ring bioreactor operation. In INMATEH Agricultural Engineering, vol. 60, no. 1, pp. 115-122.

ZASADZIEŃ, M. - MIDOR, K. 2018. Statistical process control as a failure removal improvement tool. In Acta Technologica Agriculturae, vol. 21, no. 3, pp. 124-129. 